\title{
Paracentral scotomata: a new finding after vitrectomy for idiopathic macular hole
}

\author{
Christos Haritoglou, Oliver Ehrt, Carolin A Gass, Nadine Kristin, Anselm Kampik
}

Department of
Ophthalmology,
Ludwig-Maximilians-
University,
Mathildenstrasse 8,
D-80336, Munich,
Germany
C Haritoglou
O Ehrt
C A Gass
N Kristin
A Kampik
Correspondence to:
Christos Haritoglou
Christos.Haritoglou@ak-i.med.
uni-muenchen.de
Accepted for publication
3 August 2000
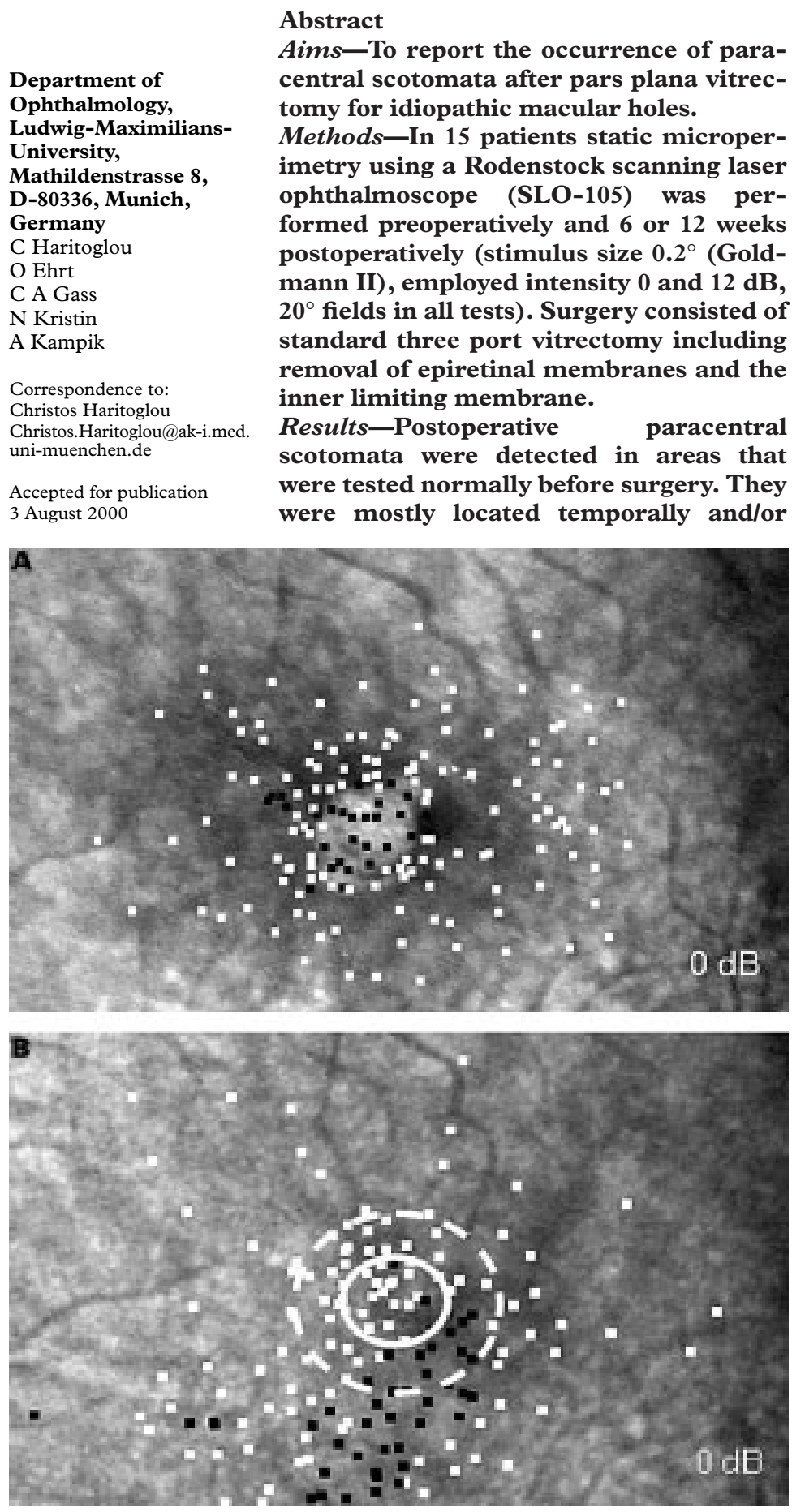

Figure 1 (A) Preoperative and postoperative (B) microperimetry of a left eye. White squares represent stimuli that were seen by the patient, black squares represent relative (12 $d B)$ or deep $(0 \mathrm{~dB})$ scotomata. The white circle marks the area of the preoperative macular defect, the broken circle the area of the preoperative neurosensory detachment.

Postoperatively a large deep scotoma inferior to the closed macular hole can be seen in an area that was tested normally before surgery. The scotoma had the shape of a nerve fibre bundle defect. inferiorly and often appeared like nerve fibre bundle defects. The greatest dimension varied from $1.2^{\circ}$ to $4.0^{\circ}(360-1200$ $\mu \mathrm{m})$, smallest dimension from $0.25^{\circ}$ to $2.0^{\circ}$ (75-600 $\mu \mathrm{m})$. In three patients more than one scotoma was observed.

Conclusion-Small, mostly asymptomatic, paracentral scotomata as a complication after vitrectomy for idiopathic macular hole have not been reported in the literature so far. Whether they are caused by trauma to the nerve fibres during surgery or other factors remains unknown.

(Br f Ophthalmol 2001;85:231-233)

Before Kelly and Wendel ${ }^{1}$ reported the successful closure of full thickness idiopathic macular holes by removal of the cortical vitreous over the macula followed by gas tamponade, this condition was considered untreatable. Along with the development of operative techniques both the anatomical success and functional results have improved..$^{2-4}$ Reported postoperative complications have included cataract, retinal detachment, retinal breaks, retinal pigment epitheliopathy, late reopening, and peripheral visual field loss. ${ }^{2-9}$ We report the occurrence of paracentral scotomata in patients after vitrectomy for macular hole, a finding that, to our knowledge, has not been described previously.

\section{Patients and methods}

Clinical examination was performed in 15 patients, six men and nine women, with a mean age of 71 years (range 63-79 years) preoperatively and 6 or 12 weeks postoperatively. The diagnosis of a macular hole was made by the presence of a full thickness neurosensory defect confirmed by high resolution cross sectional imaging of the retina provided by optical coherence tomography (OCT). Using Gass's classification scheme, ${ }^{10}$ holes were designated as stage 3 and stage 4. Only idiopathic macular holes were included.

Scanning laser ophthalmoscopy with a Rodenstock scanning laser ophthalmoscope (SLO-105) was performed at all visits. This method allows the examiner to view a real time image of the macula and assess fixation while performing microperimetry with high spatial resolution. A minimum of 80 test stimuli were distributed both in the macular and paramacular areas, covering the central $8^{\circ}$ to $10^{\circ}$ of the visual field. Stimulus size was $0.2^{\circ}$ (Goldmann II), intensity was 0 and $12 \mathrm{~dB}$. To cover the a large enough area, $20^{\circ}$ fields were used for all tests. All patients were examined 1 day before 

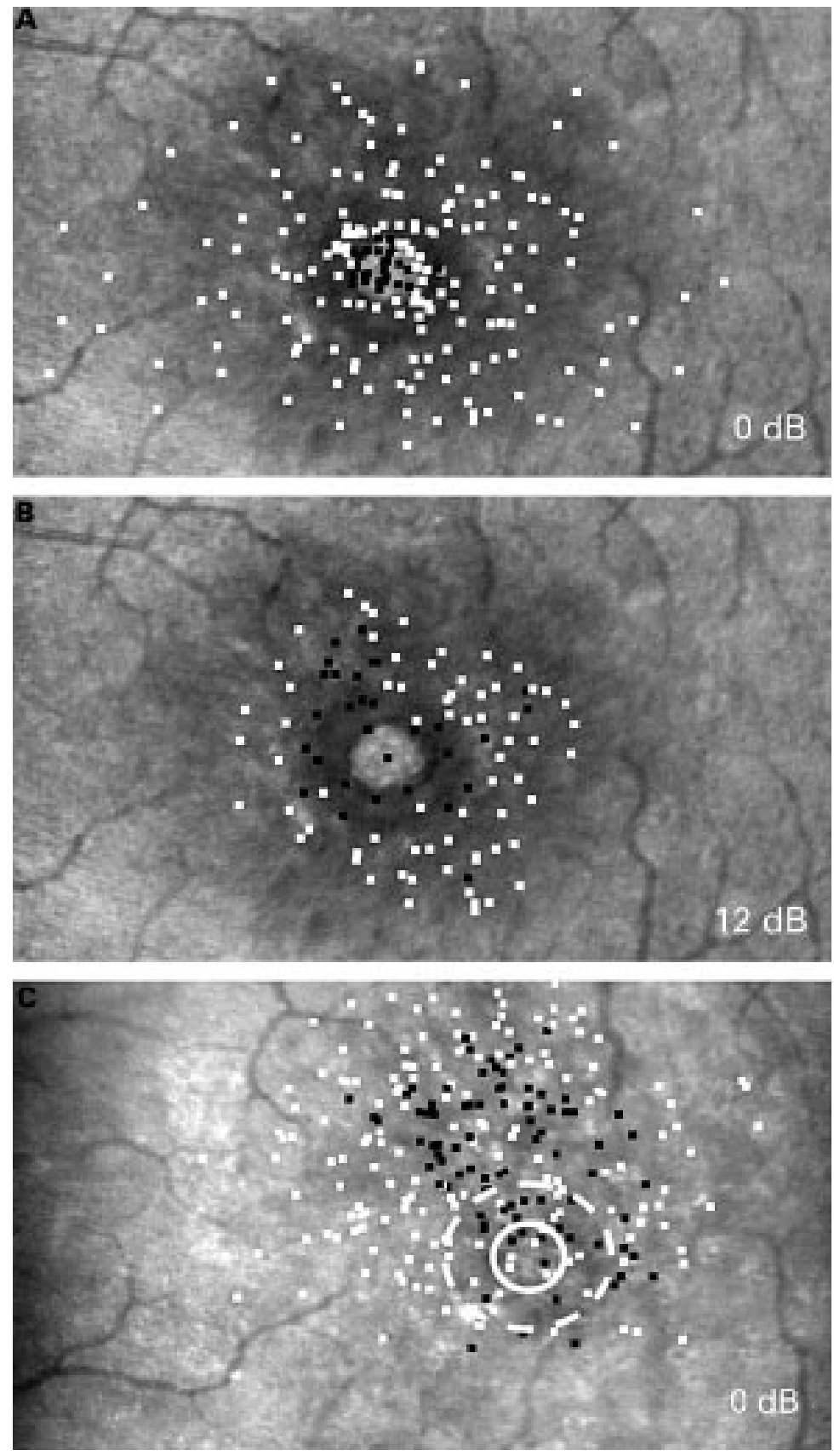

Figure 2 ( $A, B)$ Preoperative and postoperative $(C)$ microperimetry of a left eye. Preoperatively a deep scotoma in the macular hole area is seen $(A)$, which is surrounded by a relative scotoma (B). Postoperatively a large deep scotoma with irregular boundaries was found temporal to the area of the closed macular hole (C).

surgery and either $6(n=12)$ or 12 weeks $(n=3)$ postoperatively.

Surgery consisted of a standard three port vitrectomy. If the posterior hyaloid was still attached, its detachment was induced by suction with the vitrector instrument around the optic nerve head. Epiretinal membranes and/or the inner limiting membrane (ILM) were removed using a bent 28 gauge needle and an intraocular end gripping forceps. The ILM was incised and then stripped using the forceps. An attempt to peel the ILM was made in all patients. The area of removal of the ILM was intended to be one disc diameter surrounding the macular hole. Air-fluid exchange and intraocular tamponade with $\mathrm{C}_{2} \mathrm{~F}_{6}$ gas mix- ture $(15 \%)$ were then performed. Patients maintained face down positioning for at least 5 days postoperatively.

\section{Results}

Preoperative best corrected visual acuity ranged from 0.05 to 0.5 (median 0.2 ). There were 11 stage 3 holes and four stage 4 holes in this group.

Anatomical closure was achieved in 14 patients after one operation (93\%). In one patient the macular hole persisted and was successfully closed with a second operation. Best corrected visual acuity improved in all patients. Visual acuity ranged from 0.2 to 1.0 (median 0.5) postoperatively. This represented a five line increase in the median visual acuity in comparison with the preoperative data.

Preoperatively, all patients showed a central deep scotoma, the size of which corresponded to the full thickness neurosensory defect of the macula (Figs 1A, 2A). The centre of the hole was surrounded by an additional relative scotoma in the area of the visible neurosensory detachment (Fig 2B). Postoperatively the deep $(0 \mathrm{~dB})$ scotomata observed in the centre of the macular hole before surgery either disappeared $(n=11)$ (Fig 1B), decreased in size $(n=2)$, or presented as relative scotomata $(n=2)$ of reduced size. The relative scotomata around the centre of the hole had disappeared in 14 patients or become smaller in one patient postoperatively.

We observed new paracentral scotomata postoperatively in all 15 patients. Without exception, these scotomata were observed in areas that were unremarkable on preoperative microperimetry. To illustrate these findings, the results of preoperative and postoperative microperimetry of two cases were chosen (Figs 1,2). There were 13 patients with deep (Figs $1 \mathrm{~B}, 2 \mathrm{C})$ and two patients with relative scotomata. The scotomata were located either temporally and/or inferiorly to the centre of the macula in most patients. No scotoma was detected in the nasal superior area. Eleven of these new scotomata had a nerve fibre bundle defect-like appearance (Fig 1B). In two patients we observed two and in one patient three paracentral scotomata were found. In four cases they reached less than $2^{\circ}$ up to the area of preferred fixation. The longest dimensions of the scotomata varied from $1.2^{\circ}$ to $4.0^{\circ}$ $(360-1200 \mu \mathrm{m})$ and the shortest from $0.25^{\circ}$ to $2.0^{\circ}(75-600 \mu \mathrm{m})\left(1^{\circ}\right.$ corresponds with 300 $\mu \mathrm{m})$ Only four patients subjectively realised the scotoma detected in microperimetry and one of them was able to draw the shape of the defect on the Amsler chart. None of the described scotomata changed in shape, density, or size during the postoperative follow up period (mean 11 months).

\section{Discussion}

In patients with idiopathic macular holes, microperimetry with the scanning laser ophthalmoscope (SLO) has been shown to be useful in evaluating functional changes in the macula and the surrounding retina. ${ }^{11-15}$ Less 
attention has been paid to the visual field subserved by paramacular areas surrounding the hole itself.

The detection of paracentral scotomata explains our clinical impression that some patients complain of small defects in the paracentral visual field despite good postoperative results in distance and reading acuity. However, most of the patients included in this report were asymptomatic.

The origin of the observed paracentral scotomata is not completely understood. As most of them appear like nerve fibre bundle defects, one might hypothesise that our operative procedure, which includes the peeling of the ILM, is responsible for their occurrence. Interestingly, paracentral scotomata were also detected in patients in which the removal of the ILM was not successful. Nevertheless, an attempt to peel the ILM with a sharp tipped dissecting needle was made in all patients. Therefore it cannot be excluded that the observed scotomata might be due to a direct trauma to the nerve fibres during ILM peeling. However, additional (and so far unknown) causative factors have to be considered and will be the subject of further studies.

1 Kelly NE, Wendel RT. Vitreous surgery for macular holes.
2 Wendel RT, Patel AC, Kelly NE, et al. Vitreous surgery for macular holes. Ophthalmology 1993;100:1671-6.

3 Freeman WR. Vitrectomy surgery for full-thickness macular holes. Am $\mathcal{F}$ Ophthalmol 1993;116:233-5.

4 Freeman WR, Azen SP, Kim JW, et al. The Vitrectomy for Macular Hole Study Group. Vitrectomy for the treatment of full-thickness stage 3 or 4 macular holes. Results of a multicentered randomized clinical trial. Arch Ophthalmol 1997;115:11-21.

5 Ryan EH, Gilbert HD. Results of surgical treatment of recent-onset full-thickness idiopathic macular holes. Arch Ophthalmol 1994;112:359-64.

6 Park S, Marcus DM, Duker JS, et al. Posterior segment complications after vitrectomy for macular hole. Ophthalmology 1995;102:775-81.

7 Melberg NS, Thomas, MA. Visual field loss after pars plana vitrectomy with air/fluid exchange. Am F Ophthalmol 1995; vitrectomy

8 Boldt HC, Munden PM, Folk JC, et al. Visual field defects after macular hole surgery. Am f Ophthalmol 1996;122: after macul

9 Haritoglou C, Feix CA, Messmer EM, et al. Peripheral visual field defects - a rare complication after macular hole surgery. Invest Ophthalmol Vis Sci 1999;40:113.

10 Gass JDM. Idiopathic senile macular hole: its early stages and pathogenesis. Arch Ophthalmol 1988;106:629-39.

11 Acosta F, Lashkari K, Reynaud X, et al. Characterization of functional changes in macular holes and cysts. Ophthalmology 1991;98:1820-3.

12 Guez JE, Le Gargasson JF, Massin P, et al. Functional assessment of macular hole surgery by scanning laser ophthalmoscopy. Ophthalmology 1998;105:694-9.

13 Sjaarda RN, Frank DA, Glaser BM, et al. Resolution of an absolute scotoma and improvement of relative scotomata after successful macular hole surgery. Am f Ophthalmol 1993;116:129-39.

14 Sjaarda RN, Frank DA, Glaser BM, et al. Assessment of vision in idiopathic macular holes with macular microperimetry using the scanning laser ophthalmoscope. Ophthalmology 1993:100:1513-8.

15 Byhr E, Lindblom B. Preoperative measurements of macular hole with scanning laser ophthalmoscopy. Correlation with functional outcome. Acta Ophthalmol Scand 1998;76: 579-83. 